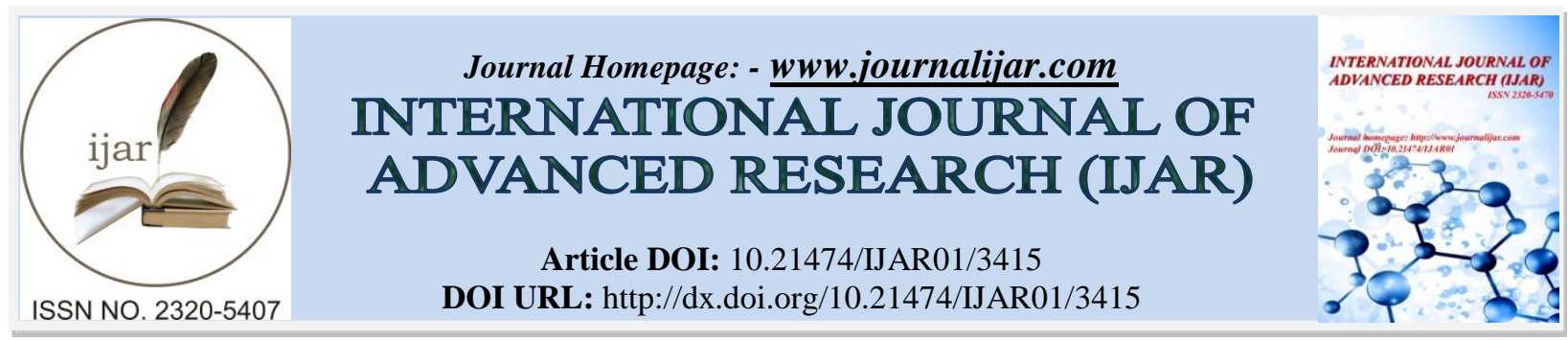

RESEARCH ARTICLE

\title{
IMPROPER SEMANTIC INTERPRETATIONS OF FOOD IDIOMATIC EXPRESSIONS BY IRAQI EFL LEARNERS.
}

Dr. Mukhalad Malik.

Department of English, Cihan University, Sulaimanyia.

\section{Manuscript Info}

Manuscript History

Received: 14 December 2016

Final Accepted: 15 January 2017

Published: February 2017

\begin{abstract}
The current paper is concerned with elaborating the improper semantic interpretations by Iraqi EFL learners concerning the performance of the idiomatic expressions. In particular, the paper shows the semantic failures of Iraqi EFL learners concerning the use of food idioms. The most important thing which it attempts to encompass is to show whether a food item in certain contexts is understood as a kind of food or as an idiomatic expression. This is mainly done through analyzing the responses of the learners when doing a test containing this type of idiomatic expressions. The study reveals that EFL learners fail when they attempt at explaining such food idioms due to various levels of semantic inefficient knowledge.
\end{abstract}

Copy Right, IJAR, 2017,. All rights reserved.

\section{Introduction:-}

This type of idioms is a very interesting field of investigation as it provides insights on how people utilize language figuratively to be more effective and as it is part of the cultural aspect of the users of that language. A pure idiom, as defined by Fernando and Flavell (1981:48), is a 'non-literal set expression whose meaning is not a compositional function of its syntactic constituents but which always has a homonymous literal counterpart.' Fernando (1996:3536) gives a more working definition of it as 'a type of non-literal, multiword expression.' The current paper attempts at showing the various levels of semantic failures of the use of such idioms when by Iraqi EFL learners. An empirical test is administered to show the attributes of semantic failures when learners explain food idiomatic expressions in specific contexts.

\section{Definition and Main Properties of Idioms:-}

There have been many attempts to define the word 'idiom'. An 'idiom' is usually understood to be as "a unit of two or more words whose meaning is not the combination of its syntactic elements" (Pinnavaia 2010: 25). Since, as this definition suggests, the whole meaning of an idiom is not inferred from the meanings of its constituents, idioms can be described as being semantically opaque expressions (Svensson 2008: 84). In fact the assumption that all idioms are opaque to the same extent is not altogether correct. It is argued that an expression can be defined as transparent when "a language user understands it without any problems, without any other previous knowledge than understanding the separate words that 18 make up the expression". Expressions which are usually characterized by a high degree of transparency are similes such as easy as pie, as good as gold and white as snow (ibid).

In other cases, an expression such as kick the bucket can be labeled as opaque, since its idiomatic meaning bears no relationship to the meanings of its constituents (Tabossi and Zardon 1993: 145).Similarly; idioms have been shown 
to range from fully frozen to fully flexible. In other words, although "[c]certain morphological and syntactic operations are allowed for virtually all idioms (e.g., insertion of an auxiliary in the phrase)", idioms vary in the extent to which they can undergo morpho-syntactic transformations without losing their idiomatic meaning. Thus, in the case of a frozen idiom like kick the bucket (i.e. to die); it is not possible, for example, to passivize the idiom (e.g. the bucket was kicked by John) and still retain the idiomatic meaning. On the other hand, in the case of a more flexible idiom like lay down the law (i.e. to give strict orders), the passivization of the idiom (e.g. The law was laid down by her father) is possible in that it does not appear to change the figurative meaning of the idiom (Peterson and Burgess 1993: 208).

The other important intrinsic property concerning idioms is that they have some apparent communicative or discourse purpose. In other words, the acceptability of an idiom's variant is dependent on the extent to which a listener/reader can infer communicative intent from the use of the idiom's variant. For example, in the decomposable idiom spill the beans, the lexical substitution of pour for spill might be considered acceptable or not. If a listener/reader is not able to infer a communicative purpose from the replacement of spill with pour, then the variant pour the beans will be viewed as a mistake Glucksberg (1993: 19).

The latter function implies that speakers/writers can express positive or negative opinions about a particular fact or event by means of idioms, or, more precisely, by exploiting the positive or negative evaluations conveyed by idioms. The reason for the use of idioms as tools to express personal opinions lies in the communicative effects that can be obtained on listeners/readers (ibid: 302 ).

\section{Analysis of Food Idiomatic Expressions:-}

This section is entirely devoted to analyse the food idiomatic expressions as they are used in various contexts focusing mainly on their non-literal meanings so as to have a better understanding of how they function in a given language. This means that the analysis will comprise the semantic level of language since such idioms fall within the study of the meanings they intend to convey and also other levels such as the culture and society in which such idioms are used.

\section{Semantic Analysis of Food Idiomatic Expressions:-}

There is no doubt that food idiomatic expressions fall within the non-literal (or figurative) study of semantics since they convey meanings which are not related to their literal interpretations at all. Many food idiomatic expressions originated from colloquial speech and slang, the others can be presented as the result of specific historical circumstances. For example: "to be worth one's salt" -is idiomatic expression meaning "someone getting a salary not for nothing," but when translated literally it means "to be worthy of salt." Although today salt is one of the cheapest products in the history of man-kind, there have been periods when the salt was equal to gold. Thus, "to be worthy of salt" reflects human rights importance. As food is a prerequisite condition of human being almost every culture it finds important ceremonial, ritual and symbolic meanings connected with lexical level of language. In general, the semantic features of the majority of food idioms can be seen as types of connotations which can be defined as "additional semantic markers which are associated with the value judgments of a speech community or of an individual speaker or writer" (Gläser 1998: 127). They are usually used to cause an emotional reaction or to emphasize something that has been written or said by the user of language. Concerning food idiomatic expressions, three major types of connotations can be recognized: expressive, stylistic and register connotations. Expressive connotations can be of various types including humorous (e.g. "to have a bun in the oven"). Stylistic connotations are usually used in conversations and can be informal (e.g. "bad egg). Finally, register markers, as a final type of connotations, usually appear in dictionaries as references to a specific field and can be related to astronomy, economics, medicinal etc. (ibid: 128).

\section{Cultural Analysis of Food Idiomatic Expressions:-}

Since the paper focuses on the use of food idiomatic expressions in contexts and why learners may fail to interpret them efficiently, it is very significant to shed light on the use of such idioms as far as their use and meanings in culture and society are concerned. This is basically due to the fact that foods have a range of cultural meanings; they communicate information in terms not only of occasion but also social status, ethnicity and wealth. These meanings, however, are not intrinsic in foodstuffs. The meanings of such idioms rely heavily on the social context in which the items are found (Murcott, 1982: 203). The preparation and consumption of food provides, moreover, a material means for expressing the more abstract significance of social systems and cultural values. It may be argued that what people are prepared to take inside their bodies reflects their social identities, and their membership of social groups. 
To view eating habits as a matter of culture is to understand that they are a product of codes of conduct and the structure of social relationships of the society in which they occur. Food, then, has both a material and a symbolic significance (ibid: 204).

\section{Methodology of the Test:-}

Brown (1989: 129) defines a test as "a method of measuring a person's ability or knowledge in a given area". A reliable test should include testees, relevant data to achieve the aims of the test, scoring of the subjects' answers to the test items and the interpretation of the response (ibid). The test is based on "A Lesson on Food Idioms" by YenLing Teresa Ting (appendix1). The test includes food idiomatic expressions used in specific context to be interpreted by those learners with answers as typical interpretations so as to compare them later on to the responses of the learners. The test is given to each learner on a sheet of paper and each one is given a proper time to read and then answer. The sample includes ten students from the fourth grade are chosen from the Department of English/ Cihan University/ Sulymania/ for the academic year 2016-2017. The responses are then analysed for the purpose of showing the kinds of the semantic failures the learners may commit while trying to explain such idioms. As far as the scoring is concerned, Harrocks and Schannover (1969:76) believe that for the purpose of objectivity of the test, a scoring scheme must be objective and accurate. In scoring the subjects' responses to the test items, the researcher depends on a 'write-wrong basis' or the ' $1-0$ ' principle by giving ' 1 mark for the correct answer and ' 0 ' for the incorrect one.

\section{Results and Analysis:-}

Within this vital section, the responses of the learners are analysed and discussed in detail so as to determine the semantic inefficient knowledge while trying to interpret the given idioms. Each failure is grouped according to the type of the semantic inefficiency or lack of knowledge.

\section{Failure due to Literal Interpretations:-}

This is the most frequent kind of the semantic failure which the responses of the learners showed. Mainly, this failure can be clearly attributed to the fact that learners did not recognize that a given food idiomatic expression is used in a non-literal sense instead of a literal one. In other words, the learners explained the idioms with regard to its literal interpretation; food stuff (as found in the test) is deemed purely food by the learners since they have a severe lack of knowledge about the non-literal use of food idiomatic expressions. The result of such explanations was entirely improper and not related at all to the intended meaning of the idiom as in the following examples:

Ex (1) "bring home the bacon means that Bob is eating a kind of meat."

Ex (2) "well I think that this guy is interested in delicious food."

Ex (3) "Mark doesn't know to choose good egg."

Ex (4) "He may not prefer tea but other kind of drinks, I think."

Ex (5) "He needs a piece of cake in his job so as not to feel hungry."

Ex (6) "we need butter for health and other things."

So the learners, as the responses clearly reveal, do not match the intended meaning; they totally interpret them as food stuff because they only took literally the meaning of the food (as for example the word 'bad' with 'egg' referring to a bad person) ignoring the other words which appear with the food expression or, in some cases, they ignored the entire idiomatic expression (as for example half-baked referring to an issue under discussion). In doing so, the entire context is ignored by the learners and this means that not recognizing that such expressions are used non-literally is a clear evidence of the fact that the learners have inefficient knowledge of the idiomaticity of food expressions and, thus, they are unaware of the communicative function of the use of such idioms. The total percentage of failure due to this factor is $25 \%$.*

* The statistical procedures are recommended and supervised by the statistical expert Assist. Prof Dr. Atheer Anwar / College of Business Administration/ University of Anbar.

Failure due to Improper Non- Literal Interpretations:-

Although some responses showed that the learners are aware that the food idioms are used non-literally, they were unable to identify the exact or intended meaning of the given food idiom. So, they had knowledge of the fact that food is used as idioms but they did not have knowledge of what they exactly mean, again the result was improper 
interpretations due to the fact that they are unfamiliar with the intended meaning as used in the given context as in the following examples:

Ex (7) "hot potatoes refer to an idea which they try to have."

Ex (8) "spill the beans is something unusual which may be difficult."

Ex (9) "one smart cookie means to get a new thing in life."

Ex (10) "it is the big thing that is not really important."

Ex (11) "we must say the truth when we talk about spill the beans."

The total percentage of failure due to this factor is $18 \%$.

Failure due to Total Lack of Semantic Knowledge:-

In some cases, learners showed total awkwardness and severe shortage of semantic knowledge. This can be seen clearly when the responses were left unanswered or they included weak performance of language as in the following examples:

Ex(12) "his noodles are ..........not clear.. noodles."

Ex (13) "chew is something that is..............not sure

The total percentage of failure due to this factor is $18 \%$.

\section{Conclusion:-}

Food idiomatic expressions are one of the important idioms used in English language in various spoken and written contexts. The main feature of such idioms is the fact that they are used non-literally to make the use of language more effective and more colorful. In most cases, they have important communicative functions and various purposes. In general, Iraqi EFL learners lack knowledge of the intended meanings and communicative functions of food idiomatic expressions due to semantic attributes. They are unaware of the non-literal aspect that such idioms have when they are used in various contexts either because they are not familiar with them or they were not exposed to such idiomatic expressions in their academic studies. In some cases, the responses of the learners show that they lack total knowledge of semantics particularly the lexical meanings of certain words. In fact, Iraqi EFL learners should be exposed to such kind of knowledge so as to have a better performance and so as to improve their skills of communications when using various kinds of idiomatic expressions.

\section{Bibliography:-}

1. Brown, Douglas. (1989). Principles of Language Learning and Teaching. New Jersey: Prentice- Hall, Inc.

2. Fernando, C., and Flavell, R. H. (1981.). On Idiom: critical views and perspectives. Exeter: University of Exeter.

3. Fernando, C. (1996). Idioms and Idiomacity. London:Penguin books.

4. Glucksberg, Sam. 1993. Idiom meanings and allusional content. LEA, Mahwah, NJ.

5. Gläser, Rosemarie. 1998. The Stylistic Potential of Phraseological Units in the Light of Genre Analysis. New York: Oxford University Press

6. Harrocks, J., and Schannover, T. (1969). Measurement for Teacher. New York: Charles E. Merril Publishing Company.

7. Murcott, Anne. "The Cultural Significance of Food and Eating."Proceedings for the Nutrition Society. Cambridge: Cambridge University Press.

8. Peterson, R. R., \& Burgess, C. (1993). Syntactic and semantic processing during idiom comprehension: Neurolinguistic and psycholinguistic dissociations. Hillsdale, NJ: Lawrence Erlbaum Associates.

9. Pinnavaia, L. (2010). Sugar and Spice....Exploring food and Drink Idioms in English. English Library: the Linguistics Bookshelf, 5. Monza: Polimetrica.

10. Svensson, Maria H. (2008). A very complex criterion of fixedness: Non-compositionality. Amsterdam/Philadelphia: Benjamins.

11. Tabossi, P., and Zardon, F. (1993). The activation of idiomatic meaning in spoken language comprehension. Hillsdale, NJ: Lawrence Erlbaum Associates. 


\section{Appendix 1:-}

Read the following passage carefully then explain the underlined idioms according to the way they are used in the passage:

Bringing Home the Bacon on the Gravy Train:-

Bob works hard to bring home the bacon ${ }^{1}$, and put bread and butter ${ }^{2}$ on his family's table. Every morning, he drags himself to his desk at the bank and faces his tedious 10-hour-a-day job. His boss, Mark, is a bad egg ${ }^{3}$ but has somehow taken a liking to Bob so he always speaks well of Bob in front of Mr. Davies, the owner and big cheese ${ }^{4}$ of the company. Mark tells Mr. Davies that Bob's the cream of the crop ${ }^{5}$ and is one smart cookie ${ }^{6}$ who uses his noodles $^{7}$. Mark likes to chew the fat ${ }^{8}$ with Bob during coffee break and discusses half-baked ${ }^{9}$ company plans with him because he trusts Bob and knows that Bob won't spill the beans ${ }^{10}$ behind his back. On these occasions, Bob tries to avoid any hot potatoes ${ }^{11}$ and, even if Mark isn't his cup of tea ${ }^{12}$, Bob makes an effort to butter him up ${ }^{13}$ by leading Mark into discussions about electronic gadgets which Mark is nuts about ${ }^{14}$. Bob really thinks that Mark is out to lunch ${ }^{15}$ and nutty as a fruitcake ${ }^{16}$, but in a nutshell ${ }^{17}$, if he polishes the apple ${ }^{18}$, his job could become a piece of cake ${ }^{19}$ and maybe one day he will find his gravy $\operatorname{train}^{20}$.

Typical Interpretations:-

\begin{tabular}{|c|c|c|c|c|c|c|c|}
\hline Idiom & Meaning & Idiom & Meaning & Idiom & Meaning & Idiom & Meaning \\
\hline 1 & Make a living & 6 & $\begin{array}{l}\text { An } \\
\text { person }\end{array}$ & 11 & $\begin{array}{l}\text { Problematic } \\
\text { issues }\end{array}$ & 16 & A little crazy \\
\hline 2 & Food & 7 & Thinks & 12 & $\begin{array}{l}\text { The type of } \\
\text { person he likes }\end{array}$ & 17 & Basically \\
\hline 3 & Scoundrel & 8 & $\begin{array}{l}\text { Share confidential } \\
\text { information }\end{array}$ & 13 & Chat & 18 & $\begin{array}{l}\text { continues to be } \\
\text { servile and } \\
\text { brown-nose his } \\
\text { boss }\end{array}$ \\
\hline 4 & Boss & 9 & $\begin{array}{l}\text { On the table but still } \\
\text { not official }\end{array}$ & 14 & Really likes & 19 & Very easy \\
\hline 5 & The best & 10 & Show admiration & 15 & $\begin{array}{l}\text { A little out of } \\
\text { touch } \\
\text { reality }\end{array}$ & 20 & $\begin{array}{lr}\text { Big } & \text { income } \\
\text { with } & \text { little } \\
\text { effort } & \end{array}$ \\
\hline
\end{tabular}

